\title{
Creatinine, calcium, citrate and acid-base in spinal cord injured patients
}

\author{
R G Burr MSc PhD, C Chem FRSC, I Nuseibeh MB ChB LMSSA FRCS(Ed)
}

National Spinal Injuries Centre, Stoke Mandeville Hospital, Mandeville Road, Aylesbury, Buckinghamshire, HP21 8AL, UK.

The aim of this work was to recognise factors responsible for reduced citrate excretion, previously reported in patients with spinal cord lesions and possibly related to the occurrence of urinary tract stone or catheter blockage. Inter alia, a reference range for creatinine in plasma $(34-88 \mu \mathrm{mol} / \mathrm{l})$ was also obtained.

Two groups of subjects were studied. The first group consisted of 64 male inpatients with spinal cord lesions and 20 male control subjects. The second group were 342 spinal patients who attended an outpatient clinic and 31 control subjects.

Plasma calcium was within the normal range but higher in patients within 1 year of onset of the cord lesion than it was later or than was found in control subjects.

Plasma $\mathrm{pH}$ and bicarbonate were within the normal range but higher in the patients than in the control subjects. When patients with urea-splitting infection were omitted the patients had a higher urinary $\mathrm{pH}$ and a lower urinary ammonium than the controls.

Urinary and plasma citrate were lower in the patients than in the controls. Urinary citrate was related to urinary potassium and creatinine clearance. Fractional renal tubular reabsorption of citrate did not differ between patients with normal renal function and control subjects. Patients with normal glomerular filtration had lower filtered load of citrate than the controls.

The coincidence of relative alkalosis and reduced citrate excretion may be relevant to the understanding of catheter blockage and urinary stone formation in spinal cord injured patients.

Keywords: paraplegia; citrate; bicarbonate; creatinine.

\section{Introduction}

In patients with spinal cord lesions some of the processes involved in catheter blockage and in calculus formation are the same. ${ }^{1}$ Citrate excretion is reduced in spinal cord injured patients, a feature that may be related to the occurrence of renal stone disease. $^{2}$

Citrate forms soluble nonionised complexes with calcium ions, thereby lowering the effective concentration of calcium in solution. ${ }^{3}$ Citrate also inhibits the formation, growth and aggregation of crystals of calcium oxalate and calcium phosphate. ${ }^{3}$ In patients without spinal cord injury, urine citrate levels are reduced in certain types of calcium renal stone disease. ${ }^{4}$ Therapy with oral citrate lowers recurrence rates in calcium stone disease. ${ }^{5}$ In spinal cord injured patients citrate excretion was reduced in patients with or without urinary stone disease. ${ }^{2}$ Citrate excretion was also low in patients who did not have urinary infection. Hypocitraturia was partly explained by low potassium excretion. ${ }^{6}$ The aim of this work was to confirm and extend these findings.

\section{Patients and methods}

All the subjects were male. Group 1 consisted of 64 patients with spinal cord lesions and 20 control subjects. The patients had been admitted for rehabilitation (28), minor 
surgery (18), pressure sores or their sequelae (sinus, bursa, abscess) (10) or for medical investigations (8) (Table I). Three had a history of bladder stone, previously removed. Eighteen had a history of kidney stone, three being stone free when studied. No patient was pyrexial or receiving alkalies or acidifying agents when studied. Informed consent was obtained. The control subjects were able bodied, in good general health and aged 19-68 (median 30) years.

On each subject two 24-hour urine collections were made with the receiver kept in ice and analysed for $\mathrm{pH}$ (by electrode), sodium, potassium (flame photometry), chloride (titration), ammonium, calcium, magnesium, phosphate, creatinine (Beckmann ASTRA), urate (spectrophotometry), citrate, isocitrate, and oxalate (enzymic methods). ${ }^{6}$ On both days venous blood samples were obtained with a minimum of venous stasis, with the subject fasting and having been in the supine position for at least 45 minutes. $\mathrm{pH}$ and blood gases, plasma sodium, potassium, chloride, calcium, inorganic phosphate, albumin, total protein, alkaline phosphatase, urate and magnesium were determined on one sample and creatinine (Beckmann ASTRA) and citrate on both. ${ }^{6}$ Plasma ionised calcium was calculated from blood $\mathrm{pH}$ and serum total calcium and proteins by two methods. ${ }^{7,8}$ Mean creatinine clearance was also calculated. The data were submitted to analysis of variance, regression and discriminant analysis. Differences between groups were tested by Student's unpaired $t$-test except for asymmetric data for which the MannWhitney $U$-test (alkaline phosphatase) and Kruscal-Wallace (urine calcium) tests were used.

A separate urine sample from each patient was sent for bacteriological culture. ${ }^{6}$

Group 2 consisted of 342 patients seen at an outpatient clinic and 31 healthy control subjects. $\mathrm{pH}$, ammonium, citrate and creatinine were determined in urine samples obtained from the patients for routine microscopy and bacteriological culture and in random urine samples from the control subjects.

\section{Results}

Group 1

Figures 1 and 2 show the creatinine data. Urinary creatinine was lower in the patients than in the control subjects and fell with diminishing creatinine clearance. Plasma creatinine was also lower in patients than controls but rose with diminishing creatinine clearance. Plasma creatinine was in the

Table I Group 1. Details of the patients studied

\begin{tabular}{|c|c|c|}
\hline & \multicolumn{2}{|c|}{ Creatinine clearance } \\
\hline & Under $80 \mathrm{ml} / \mathrm{min}$ & $80 \mathrm{ml} / \mathrm{min}$ or more \\
\hline Total number & 25 & 39 \\
\hline Positive urine culture & 21 & 19 \\
\hline Stone formers & 10 & 11 \\
\hline \multicolumn{3}{|l|}{ Cord lesion } \\
\hline Cervical & 9 & 21 \\
\hline Thoracic & 14 & 11 \\
\hline Lumbar & 2 & 7 \\
\hline Complete & 19 & 27 \\
\hline Incomplete & 6 & 12 \\
\hline Age range (median) & $21-62(37)$ yrs & $18-69(35)$ yrs \\
\hline \multicolumn{3}{|l|}{ Duration of lesion } \\
\hline$<1 \mathrm{yr}$ & 6 patients & 13 patients \\
\hline range (median) & 3-11 (7) months & 3-11 (5) months \\
\hline$>1 \mathrm{yr}$ & 19 patients & 26 patients \\
\hline range (median) & $2.8-43(15)$ yrs & 13 months -26 yrs ( $11 \mathrm{yrs})$ \\
\hline Creatinine clearance & $30-70(66)$ & \\
\hline
\end{tabular}




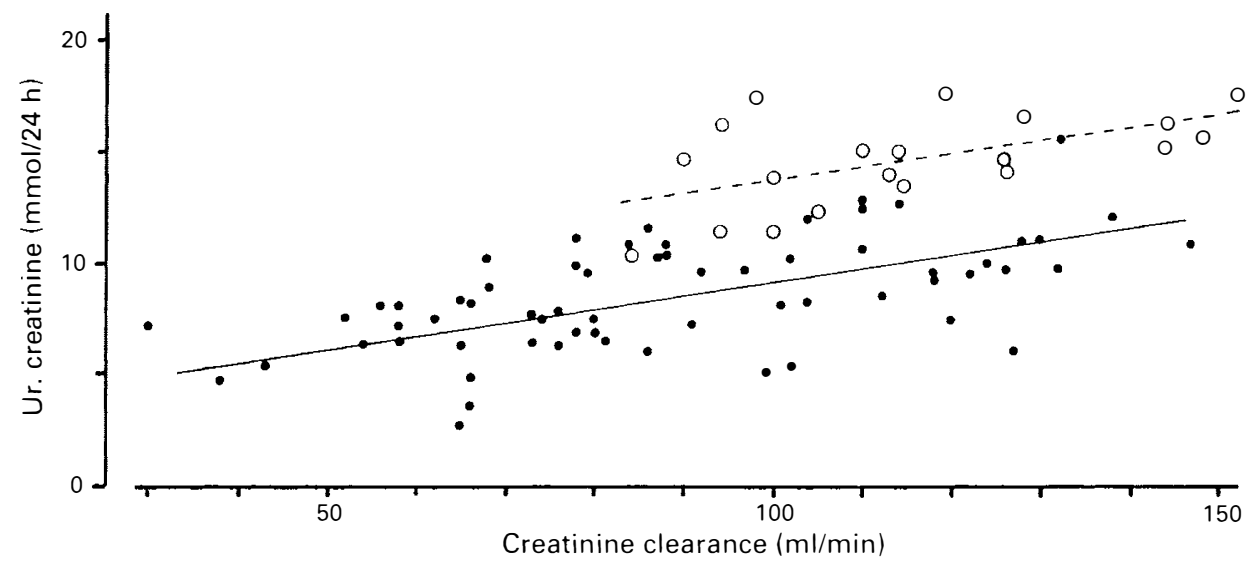

Figure 1 Group 1. Twenty-four hour urinary creatinine and creatinine clearance in control subjects (open circles) and in patients (closed circles). Regressions for controls (broken line) and patients (continuous line).

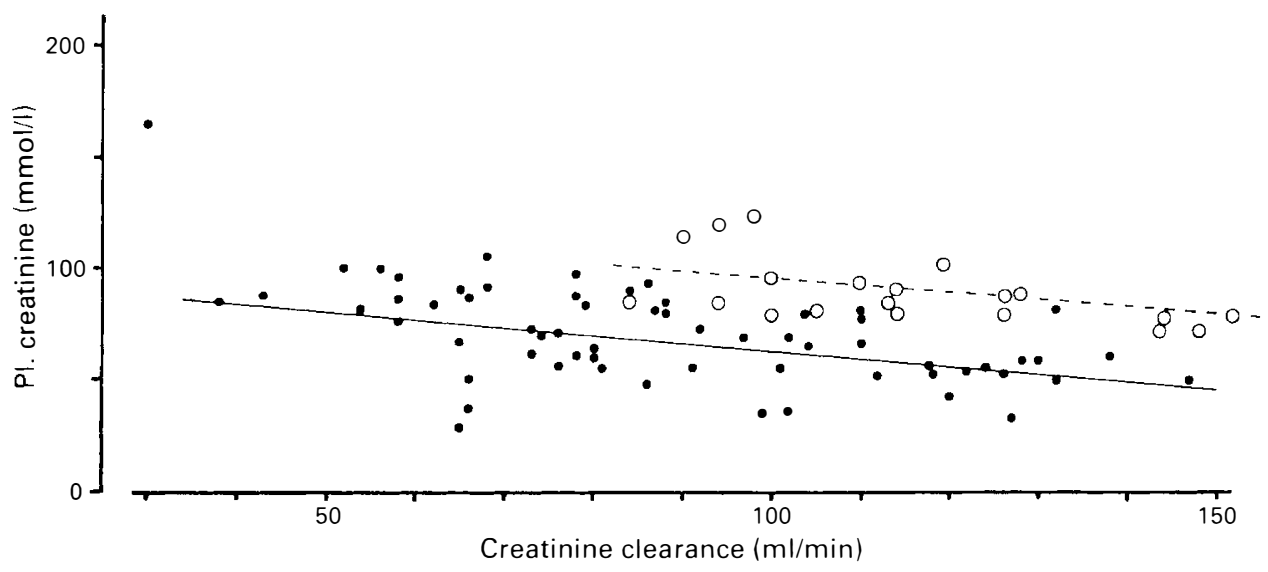

Figure 2 Group 1. Plasma creatinine and creatinine clearance in control subjects (open circles) and in patients (closed circles). Regressions for controls (broken line) and patients (continuous line).

range $34-88 \mu \mathrm{mol} / 1$ for patients whose creatinine clearance was $80 \mathrm{ml} / \mathrm{min}$ or more and $74-124 \mu \mathrm{mol} / 1$ for control subjects.

Table II shows the results for control subjects and patients with creatinine clearance of $80 \mathrm{ml} / \mathrm{min}$ or more. Urinary sodium, potassium, magnesium, phosphate, chloride and citrate were lower and urinary volume was higher in the patients than in the controls. Plasma citrate and albumin were lower and $\mathrm{pH}$ and standard bicarbonate higher in the patients than in the control subjects.
Graphical plotting of $\mathrm{pH}$ and ammonium (Fig 3) revealed 17 patients with urea-splitting infection. Based on these data a $\mathrm{pH}$ ammonium quotient $(\mathrm{NH} 4+40 . \mathrm{pH})$ was defined. When the quotient was greater than 310 , urea-splitting infection was present. When these patients were omitted, urinary $\mathrm{pH}$ and ammonium were significantly correlated $(r=-0.29)$ and $\mathrm{pH}$ was higher and ammonium lower in the patients than in the controls (Table II).

The regression coefficient relating corrected and ionised calcium in plasma was 
Table II Group 1: Results in subjects with creatinine clearance $>80 \mathrm{ml} / \mathrm{min}$

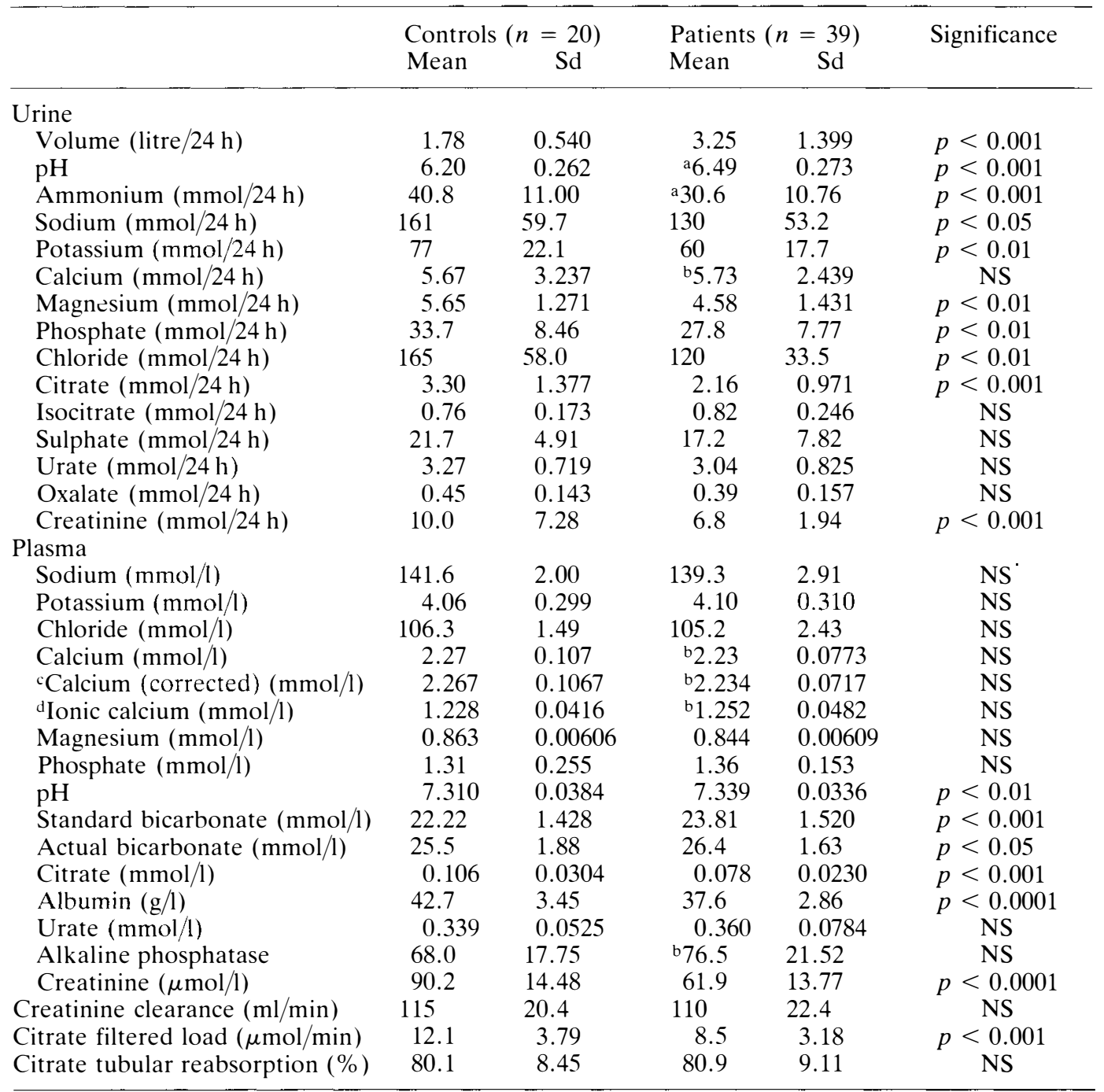

aPatients with urinary (ammonium $+40 . \mathrm{pH})>310$ omitted

bPatients with duration of cord lesion $<1 \mathrm{yr}$ omitted

'Obtained by calculation (3)

dObtained by nomogram (4)

0.64. Urinary calcium and total, corrected and ionised calcium in plasma were higher within 1 year of onset of the cord lesion than they were later (Table III), but did not differ between control subjects and patients with cord lesion more than 1 year of onset.

Filtered load of citrate (plasma citrate $x$ creatinine clearance) was reduced in the patients.
Percent tubular reabsorption of citrate

$$
100\left[\frac{1-(\text { citrate clearance })}{\text { (creatinine clearance })}\right]
$$

did not differ between patients and controls, however. Plasma citrate and actual bicarbonate levels were significantly correlated $(r=-0.28)$. 


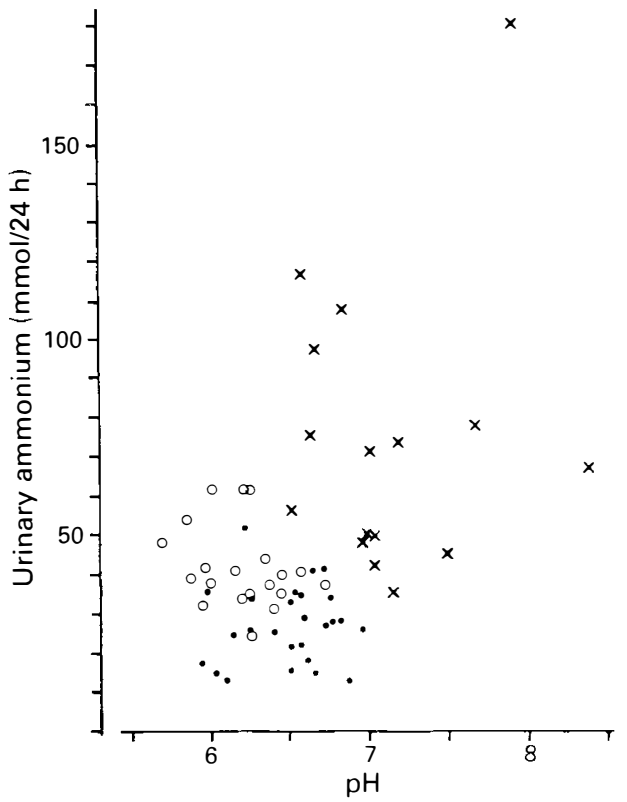

Figure 3 Group 1. Twenty-four hour urinary $\mathrm{pH}$ and ammonium excretion in control subjects (open circles), in patients without urinary infection (closed circles) and in patients with ureasplitting infection (crosses).

Among patients with a normal creatinine clearance, stone formers had a significantly lower sulphate, isocitrate and creatinine excretion and higher urinary volumes than the patients with no history of stone disease.

Multivariate analysis was carried out on the data from all patients by sequential single and multiple regression techniques. Urinary ammonium excretion correlated with plasma standard bicarbonate and creat- inine clearance (Fig 4) and urinary citrate excretion with urinary potassium and creatinine clearances (Fig 5).

Table IV shows the effects of impaired renal function. Urinary phosphate, isocitrate, sulphate and urate and citrate filtered load were reduced but plasma citrate was elevated in patients with reduced creatinine clearance.

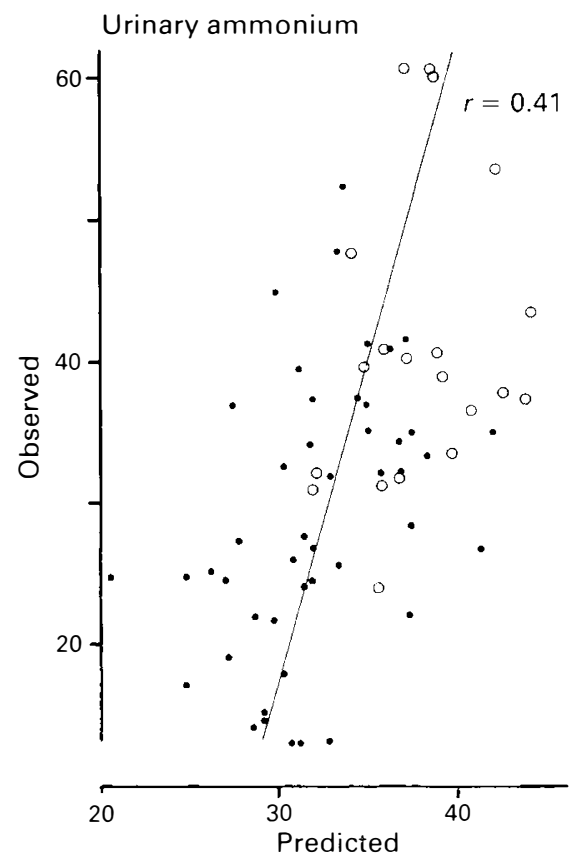

Figure 4 Group 1. Urinary ammonium as a function of standard bicarbonate (SBC) and creatinine clearance (CC). Patients with impaired renal function included. Predicted urinary ammonium $=70.391456-2.096563$. SBC + $0.123436 . C C$. $R$ squared (adjusted) $=0.1707$.

Table III Group 1. Data in patients related to duration of cord lesion. Statistically significant results only are shown

\begin{tabular}{|c|c|c|c|c|c|}
\hline & \multicolumn{2}{|c|}{$\begin{array}{l}\text { Duration }<1 \mathrm{yr} \\
\quad(n=19)\end{array}$} & \multicolumn{2}{|c|}{$\begin{array}{c}\text { Duration }>1 \mathrm{yr} \\
(n=44)\end{array}$} & \multirow[t]{2}{*}{ Significance } \\
\hline & Mean & SD & Mean & SD & \\
\hline Urine calcium ( $\mathrm{mmol} / 24 \mathrm{~h})$ & 8.86 & 4.853 & 5.71 & 2.288 & $p<0.01$ \\
\hline Plasma calcium $(\mathrm{mmol} / \mathrm{l})$ & 2.32 & 0.081 & 2.24 & 0.086 & $p<0.001$ \\
\hline Plasma calcium (corrected)a $(\mathrm{mmol} / \mathrm{l})$ & 2.320 & 0.0832 & 2.232 & 0.0717 & $p<0.001$ \\
\hline Plasma ionised calciumb $(\mathrm{mmol} / \mathrm{l})$ & 1.289 & 0.0382 & 1.257 & 0.0468 & $p<0.02$ \\
\hline
\end{tabular}

a obtained by calculation (3)

${ }^{b}$ obtained by nomogram (4) 


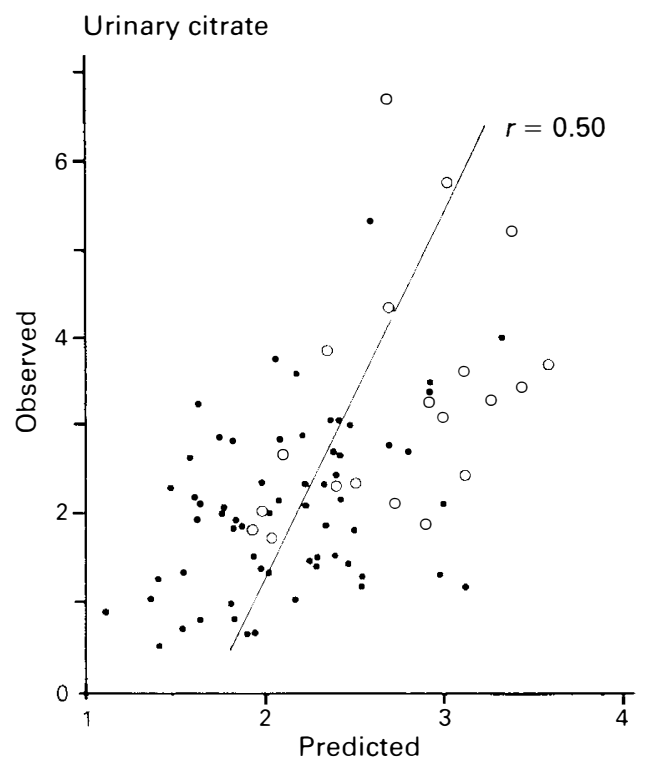

Figure 5 Group 1. Urinary citrate $(\mathrm{UCt})$ as a function of urinary potassium (UK) and creatinine clearance (CC). Patients with impaired renal function included. Predicted UCt $=0.097921+0.020728 . \mathrm{UK}+0.009157 . \mathrm{CC} . \mathrm{R}$ squared $($ adjusted $)=0.2543$.

\section{Group 2}

For 201 patients that showed no growth on culture and for the control subjects mean urinary $\mathrm{pH}$ were 6.51 and 5.98 respectively $(p<0.0001)$. The corresponding ammonium values were 15.5 and $41.7 \mathrm{mmol} / 1$ $(p<0.0001)$. There was a significant negative correlation between $\mathrm{pH}$ and ammonium concentration (Fig 6). The patients with urinary infection had mean $\mathrm{pH} 6.83$ and mean ammonium concentration $21.4 \mathrm{mmol} / 1$, which were both elevated $(p<0.001)$ compared with those with no infection. Mean citrate concentration and citrate/creatinine ratio in patients with or without urinary infection were 1.20 and $1.22 \mathrm{mmol} / 1$, and 0.58 and 0.54 respectively, differences that were not statistically significant.

\section{Discussion}

Reduced urinary creatinine in spinal patients (Fig 1) is related to the decline in muscle mass that follows a cord lesion. ${ }^{9}$ Creatinine excretion is also known to be reduced in renal failure. ${ }^{10}$ The present data show reduced creatinine excretion when less severe renal impairment is present. When renal function is normal, plasma creatinine is reduced in spinal patients (Fig 2). This has been reported previously, ${ }^{9,11}$ but to the authors' knowledge a reference range for plasma creatinine in male spinal patients has not been published until now. Creatinine production in women is $77.1 \%$ of that in men. ${ }^{11}$

To exclude effects that may have been related to impaired renal function, subjects

Table IV Group 1. Results in patients with creatinine clearance more or less than $80 \mathrm{ml} / \mathrm{min}$. Statistically significant results only are shown

\begin{tabular}{|c|c|c|c|c|c|}
\hline & \multicolumn{4}{|c|}{ Creatinine clearance } & \multirow[t]{3}{*}{ Significance } \\
\hline & \multicolumn{2}{|c|}{$\begin{array}{c}>80 \mathrm{ml} / \mathrm{min} \\
(n=39)\end{array}$} & \multicolumn{2}{|c|}{$\begin{array}{c}<80 \mathrm{ml} / \mathrm{min} \\
(n=25)\end{array}$} & \\
\hline & Mean & $\mathrm{SD}$ & Mean & SD & \\
\hline \multicolumn{6}{|l|}{ Urine } \\
\hline Phosphate $(\mathrm{mmol} / 24 \mathrm{~h})$ & 28.1 & 7.83 & 21.8 & 7.94 & $p<0.01$ \\
\hline Isocitrate $(\mathrm{mmol} / 24 \mathrm{~h})$ & 0.82 & 0.246 & 0.68 & 0.264 & $p<0.05$ \\
\hline Sulphate $(\mathrm{mmol} / 24 \mathrm{~h})$ & 17.2 & 7.68 & 10.7 & 4.84 & $p<0.05$ \\
\hline Urate $(\mathrm{mmol} / 24 \mathrm{~h})$ & 3.04 & 0.825 & 2.44 & 0.667 & $p<0.01$ \\
\hline Creatinine $(\mathrm{mmol} / 24 \mathrm{~h})$ & 6.8 & 1.94 & 4.97 & 1.36 & $p<0.001$ \\
\hline Plasma citrate $(\mathrm{mmol} / \mathrm{l})$ & 0.078 & 0.0230 & 0.094 & 0.0319 & $p<0.05$ \\
\hline Creatinine clearance $(\mathrm{ml} / \mathrm{min})$ & 110 & 22.4 & 65 & 11.9 & $p<0.001$ \\
\hline Citrate filtered load $(\mu \mathrm{mol} / \mathrm{min})$ & 8.5 & 3.18 & 6.0 & 2.11 & $p<0.01$ \\
\hline
\end{tabular}




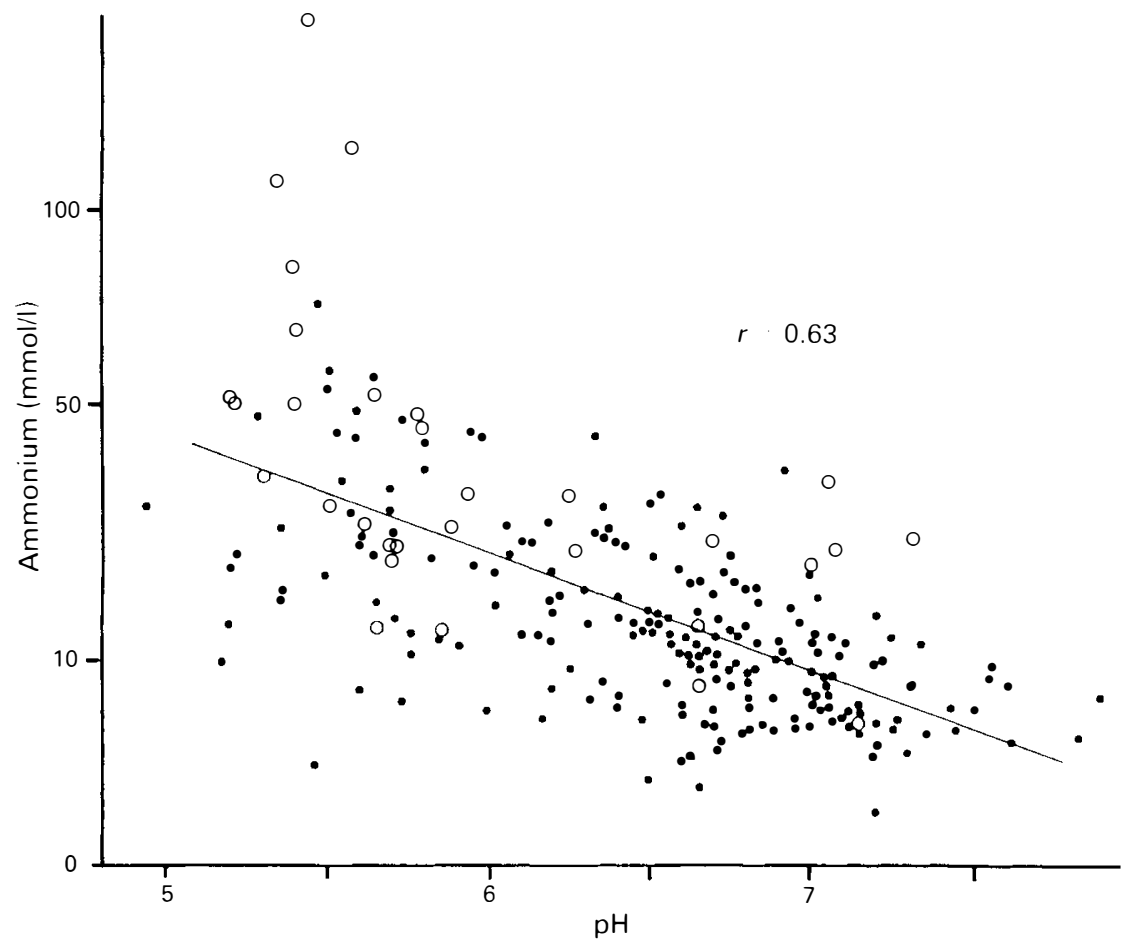

Figure 6 Group 2. Urinary $\mathrm{pH}$ and ammonium concentration in urine samples from 31 control subjects (open circles) and 201 outpatients with no urinary infection (closed circles). Ammonium as square root. Correlation coefficient $(r)=0.63$.

with creatinine clearance less than $80 \mathrm{ml} / \mathrm{min}$ are omitted from the data of Table II. Increased urinary volume in the patients is attributed to the practice of encouraging a high fluid intake. Reduced sodium, potassium, magnesium, chloride and phosphate in the patients was probably related to diet. The patients had reduced energy expenditure and therefore lower appetite than the control subjects, most of whom were physically active members of the hospital staff.

An elevated urinary $\mathrm{pH}$ is expected in patients with urinary tract infection, but it is then associated with an increased ammonium concentration. In health there is an inverse relation between urinary $\mathrm{pH}$ and the excretion of ammonium. ${ }^{12}$ Plotting urinary ammonium against $\mathrm{pH}$ permits recognition of the presence of urea-splitting infection (Fig 3). ${ }^{13}$ Values of the quotient (ammonium $+40 . \mathrm{pH})$ in control subjects were 310 or less. When patients with elevated quotient were excluded, the remaining patients had lower urinary ammonium than the control subjects (Table II) and there was a significant negative correlation between urinary $\mathrm{pH}$ and ammonium. The association of raised $\mathrm{pH}$ with lowered ammonium implies a metabolic cause, consistent with the elevated blood $\mathrm{pH}$ and bicarbonate also observed in these patients. The results from group 2, using fresh urine samples examined without delay, confirmed this relationship (Fig 6) as did the correlation of urinary ammonium to standard bicarbonate and creatinine clearance (Fig 4).

The small elevation of blood $\mathrm{pH}$ (within the normal range) observed in the patients in this study was unexpected. Possible reasons may be suggested. Firstly, spinal injured patients have reduced muscular activity and therefore a reduced level of muscle metabolism compared with able bodied persons. 
Metabolic activity of muscle tissue results in production of acid. While this is only appreciable during vigorous exercise, significant differences in metabolic acid production have been reported both from normal activity in humans ${ }^{14}$ and during immobilisation in animals. ${ }^{15}$ The difference in blood $\mathrm{pH}$ observed in this study may thus be due to the difference in metabolic acid production between normally active and paralysed subjects. The blood samples were all taken after a night's rest. A second possible explanation is that there was a dietary difference. Spinal patients have reduced energy output and therefore reduced appetite. It is possible that appetite for proteins is lowered more than appetite for calories. If so, patients will have relative reduction in acid ash content of the diet compared with nonparaplegic subjects. In consequence patients' urines will be less acidic than control subjects' urines. Further work is required to investigate these possibilities.

Total, corrected and ionised calcium in plasma were relatively elevated (though within the normal range) in patients within 1 year of onset of the cord lesion (Table III). In this study corrected and ionised calcium denote two methods of deriving the physiologically active fraction of calcium in blood plasma. Both methods involved correcting total calcium for $\mathrm{pH}$, albumin and total protein. Considering the difference in plasma protein levels it was interesting that these calculated values were not more different between patients and controls. Elevated $\mathrm{pH}$ and lowered proteins have opposing effects on the correction, however. When protein only was used as a basis for calculation the differences were much greater. Elevation of plasma ionised calcium has been reported previously in immobilised healthy subjects ${ }^{16}$ but few data have been published on spinal injured patients.

Urinary infection, which is considered to lower urinary citrate, ${ }^{17}$ was present in nearly $60 \%$ of patients. There was however no significant correlation between the presence of infection and citrate excretion in either group 1 or group 2. Low urinary citrate occurs in spinal patients even in those who are apparently free of infection ${ }^{2}$ and has been found to relate to low urinary potassium. ${ }^{6}$ In this study plasma citrate was also low in the patients (Table II). Tubular reabsorption of citrate did not differ between patients and controls. Low urinary excretion of citrate was associated with reduced filtered load. It is possible that these findings are the result of the operation of opposing processes.

Elevation of plasma bicarbonate leads to reduced tubular reabsorption, and therefore increased urinary excretion, of citrate. Potassium depletion has the opposite effect. ${ }^{18.19}$ These opposing effects may have cancelled each other leading to an apparently normal rate of tubular reabsorption. Citrate excretion correlated with both urinary potassium and creatinine clearance (Fig 5).

Plasma citrate is lowered when dietary intake of citrate is low and when there is gastrointestinal malabsorption. ${ }^{19}$ It follows that reduced plasma citrate in these patients may have been related to dietary intake. There was, however, no correlation with urinary sodium, potassium, chloride, magnesium or phosphate. The observation of increased plasma citrate in patients with impaired renal function agrees with the findings of Marangella. ${ }^{20}$

In the patients with urinary tract stone disease increased urinary volume was probably due to advice to maintain a high fluid intake. No explanation can be offered for the other differences observed. It is important, in studies such as this, to take account of differences in renal function between patients with and without stone disease.

An elevated urinary $\mathrm{pH}$ is a feature of both the formation of urinary stones and the blockage of indwelling urinary catheters. ${ }^{1}$ Low urinary citrate is a known risk factor for calcium stone disease. The common occurrence of elevated $\mathrm{pH}$ and low citrate in spinal patients deserves further study in relation to these troublesome complications.

\section{Acknowledgement}

We are indebted to Dr B S Shine for blood and urine biochemical analyses. 


\section{References}

1 Burr RG, Nuseibeh IM (1993) Blockage of indwelling urinary catheters: the roles of urinary composition. the catheter, medication and diet. Paraplegia 31: 234-241.

2 Burr RG, Nuseibeh I (1985) Biochemical studies in paraplegic renal stone formers. 2. Urinary excretion of citrate, inorganic pyrophosphate, silicate and urate. Br J Urol 57: 275-278.

3 Fleisch HF (1978) Inhibitors and promotors of stone formation. Kidney Int 13: 361-371.

4 Nicar MJ, Skurla C, Sakhee K, Pak CYC (1983) Low urinary citrate excretion in nephrolithiasis. Urology' 21: $8-14$.

5 Pak CYC, Fuller C, Sakhee K, Preminger GM. Britton F (1985) Long-term treatment of calcium nephrolithiasis with potassium citrate. J Urol 134: 11-19.

6 Burr RG, Nuseibeh I (1990) Citrate excretion in spinal cord patients. Paraplegia 28: 496-504.

7 Moore EW (1970) Ionised calcium in normal serum, ultrafiltrates and whole blood determined by ion exchange electrodes. J Clin Invest 49: 318-334.

8 Siggaard-Andersen O, Thode J. Fogh-Andersen N (1983) Nomograms for calculation of the concentration of ionised calcium of human blood plasma from total calcium, total protein and or albumin and $\mathrm{pH}$. Scand $J$ Clin Lab Invest 43: 165: 57-64s.

9 Mirahmadi MK, Byrne C, Barton C, Penera N. Gordon S, Vaziri ND (1983) Prediction of creatinine clearance from serum creatinine in spinal cord injury patients. Paraplegia 21: 23-29.

10 Mitch WE, Collier VU, Walser M (1980) Creatinine metabolism in chronic renal failure. Clin Sci 58: $327-335$.

11 Mohler JL, Barton SD, Blouin RA, Cowen DL. Flanigan RC (1986) The evaluation of creatinine clearance in spinal cord injury patients. J Urol 136: 366-369.

12 Wrong O, Davies HEF (1959) The excretion of acid in renal disease. Quart J Med 28: 259-313.

13 Burr RG, Nuseibeh I (1985) Biochemical studies in paraplegic renal stone formers. 1. Plasma biochemistry and urinary calcium and saturation. Br J Urol 57: 269-274.

14 Austin WH (1972) The influence of normal activity on the acid-base status of venous blood. J Maine Med Assoc 63: $12-13$.

15 Young DR, Yeh I, Swenson RS (1983) Metabolic acidosis during immobilisation in monkeys. Calcif Tissue Int 35: 472-476.

16 Heath H III, Earll JM, Schaaf M, Piechocki JT. Li T-K (1972) Serum ionised calcium during bed rest in fracture patients and normal men. Metabolism 21: 633-640.

17 Conway N, Maitland AIL, Rennie JB (1949) The urinary citrate excretion in patients with renal calculi. $B r$ J Urol 21: $30-38$.

18 Simpson DP (1983) Citrate excretion: a window on renal metabolism. Am J Physiol 244: F223-234.

19 Rudman D, Dedonis JL, Fountain MT. Chandler JB. Gerron GG. Fleming GA et a! (1980) Hypocitraturia in patients with gastrointestinal malabsorption. $N$ Engl J Med 303: 657-661.

20 Marangella M, Vitale C, Manganaro M, Cosseddu D. Martini C. Petrarulo M et al (1991) Renal handling of citrate in chronic renal insufficiency. Nephron 57: $439-443$. 